Gut, 1982, 23, 226-234

\title{
Testosterone metabolism by the rat gastrointestinal tract, in vitro and in vivo
}

\author{
M J G FARTHING, G P VINSON, C R W EDWARDS, AND A M DAWSON \\ From the Department of Gastroenterology and Endocrinology, St Bartholomew's Hospital, London, and the \\ Department of Biochemistry, St Bartholomew's Medical College, London
}

SUMMARY We have shown previously that the capacity of the jejunal mucosa to oxidise testosterone to the weaker androgen, androstenedione, by the enzyme $17 \beta$-hydroxysteroid dehydrogenase $(17 \beta$ HSD), is considerable. The present study extends these earlier observations by measuring $17 \beta$-HSD activity in different regions of the gastrointestinal tract, by investigating the potential for testosterone metabolism by slices and everted sacs of rat jejunum, and estimating the contribution of intestinal testosterone metabolites to circulating levels of plasma androgens, by portal vein sampling in the rat, in vivo. 17 $\beta$-HSD activity in homogenates of gastric and duodenal mucosa was significantly higher than that in jejunum, and was also present in ileum and colon. In addition to androstenedione, slices and everted sacs of rat jejunum produced various metabolites, one of which was probably dihydrotestosterone. It was not, however, a major metabolite in vivo. It is suggested that $5 \alpha$-reduction may be favoured in vitro by a lower oxidation-reduction potential resulting from tissue anoxia. The major portal vein metabolite was androstenedione, the same major metabolite produced by mucosal homogenates. We conclude that oxidation of testosterone is the major metabolic pathway in intestinal mucosa and the capacity of the gastrointestinal tract to reduce the potency of testosterone is considerable. Our findings suggest that the gut, rather than the liver, is responsible for the failure of oral testosterone to provide effective androgen replacement therapy. The qualitative difference in testosterone metabolism between in vitro and in vivo preparations emphasises the need for caution in the interpretation of similar in vitro experiments.

In a previous study we demonstrated that homogenates of rat and human jejunal mucosa can oxidise testosterone to the weaker androgen androstenedione. ${ }^{1}$ This conversion was independent of gut bacteria. The enzyme responsible for this conversion, 17 $\beta$-hydroxysteroid dehydrogenase (17 $\beta$-HSD), was present at high specific activity and the overall capacity of the small intestine to perform this conversion appeared considerable. This suggested that the gut, like other nonendocrine tissues such as skeletal muscle, ${ }^{2}{ }^{3}$ lung, ${ }^{4}$ and adipose tissue,,$^{5} \cdot{ }^{6}$ may play a significant role in the peripheral metabolism of testosterone.

Previous reports ${ }^{7-11}$ have indicated that mammalian intestinal mucosa is also capable of reducing testosterone in relatively minor amounts to a variety of $5 \alpha$ reduced metabolites, including the more potent metab-

- Address for correspondence: Dr M J G Farthing, Tufts University School of Medicine, Department of Medicine, Division of Geographic Medicine, Box 22, 136 Harrison Avenue, Boston, MA 02111, USA.

Received for publication 13 July 1981 olite of testosterone found in androgen target organs, ${ }^{3}$ dihydrotestosterone.

The present study was designed to extend earlier observations of $17 \beta$-HSD activity in the gut, to investigate the potential for further metabolism of testosterone by slices and everted sacs of rat jejunum, and to estimate the possible contribution of intestinal testosterone metabolites to circulating levels of plasma androgens by continuous portal vein sampling in vivo, in the rat.

\section{Methods}

ANIMALS

Male Wistar rats bred in the animal house at St Bartholomew's Hospital Medical College, weighing 200-260 g, were used in the following experiments.

TISSUE PREPARATION

Homogenates of gastric, duodenal, mid-jejunal, midileal, and colonic mucosa were prepared in KrebsRinger bicarbonate buffer ( $\mathrm{pH} \mathrm{7.4)}$ with D-glucose (11 
$\mathrm{mM}$ ) as described previously for jejunum. ${ }^{1}$ Protein concentration of homogenates was determined by the method of Lowry et al. ${ }^{17}$ Transverse slices and everted sacs of jejunum were prepared according to established techniques, ${ }^{18} 14$ and production of testosterone metabolites was expressed per $100 \mathrm{mg}$ wet weight of intestine.

\section{INCUBATION PROCEDURE}

$17 \beta-H S D$ assay

Mucosal homogenates from four male rats were incubated within 30 minutes of preparation in $25 \mathrm{ml}$ conical flasks in Krebs-Ringer bicarbonate buffer with glucose (KRBG) with testosterone $\left[1,2,6,7-{ }^{3} \mathrm{H}\right]$-testosterone $1.0 \times 10^{6} \mathrm{cpm}$ and unlabelled testosterone to produce a final substrate concentration of $4.0 \times 10^{-5} \mathrm{M}$ - that is, greater than 10 times the apparent $K_{m}$ :-and the cofactor for $17 \beta$-HSD, NADP $\left(4.0 \times 10^{-4} \mathrm{M}\right)$ such that the rate of androstenedione production was proportional to the time of incubation and the protein content of homogenate. Incubations were performed for 20 minutes and the final protein concentrations of the homogenates were maintained between $0.5-1.0 \mathrm{mg} / \mathrm{ml}$ as established previously. ${ }^{1} 17 \beta$-HSD activity was expressed in pmol androstenedione per $\mathrm{mg}$ protein per minute. Control flasks containing substrate but no homogenate were carried through the entire procedure in all experiments. All $17 \beta$-HSD assays were performed in duplicate and different mucosal homogenates from the same rat were assayed together. The reaction was stopped by immediate extraction with anhydrous diethyl ether.

\section{Slices and everted sacs of jejunum}

Testosterone $\left(4.0 \times 10^{-6} \mathrm{M}\right.$ including $1.0-2.0 \times 10^{6} \mathrm{cpm}$ $\left[{ }^{3} \mathrm{H}\right]$-testosterone) in KRBG solution was incubated with freshly prepared slices or everted sacs of rat jejunum, without added cofactors, at $37^{\circ} \mathrm{C}$ and the medium was bubbled throughout the incubation with $95 \% \mathrm{O}_{2} / 5 \% \mathrm{CO}_{2}$. In everted gut sac experiments testosterone was added only to the mucosal medium. D-glucose concentration was determined in mucosal and serosal media of everted sacs by the glucose oxidase method ${ }^{15}{ }^{16}$ and the development of a concentration gradient between these media ${ }^{14}$ was used as an index of metabolic integrity of the gut sac mucosa. Preliminary experiments with 54 jejunal sacs incubated for periods up to four hours showed that a concentration gradient for D-glucose was demonstrable after approximately 30 minutes and increased up to two hours. In the present studies, tissues were incubated for up to 60 minutes. Sacs were incubated in pairs, and were excluded from the study if they failed to achieve a D-glucose gradient appropriate to the time of incubation.

EXTRACTION AND SEPARATION OF METABOLITES Incubation media and tissue samples after homogenisation were extracted in 10 volumes anhydrous diethyl ether and the testosterone metabolites separated by Celite-propylene glycol column chromatography as described previously. ${ }^{1}$ Column fractions were counted in a Packard Tri-carb liquid scintillation spectrometer (3380) either singly or in pooled groups corresponding to androgen peaks. Quantification of androgen metabolites was achieved by integration of the peaks of radioactivity obtained by column chromatography, subtraction of radioactivity in equivalent column fractions of control incubations without tissue, and expressing the values for each peak as a fraction of the total radioactivity. No correction was made for procedural losses in view of the consistency of quantitative recoveries of standard tritiated androgens reported previously. ${ }^{1}$

\section{ACID HYDROLYSIS OF STEROID CONJUGATES}

The aqueous phase remaining after ether extraction of samples obtained from incubations of testosterone with everted jejunal sacs was subjected to acid hydrolysis by addition of concentrated hydrochloric acid to reduce the $\mathrm{pH}$ to less than $1 \cdot 0$. Samples were incubated at room temperature for 48 hours, re-extracted with 10 volumes diethyl ether, and subjected to further Celite column chromatography.

\section{FURTHER IDENTIFICATION OF METABOLITES}

Further evidence for the identity of androstenedione, the major testosterone metabolite produced by intestinal mucosal homogenates, was reported previously. ${ }^{1}$

Fractions obtained by Celite column chromatography of mucosal and serosal media from everted jejunal sacs, after incubation with testosterone, were examined further by gas-liquid chromatography. Methods were developed from those used in other applications. ${ }^{17-19}$ The gas chromatography used was a Pye series 104, equipped with a ${ }^{6} \mathrm{Ni}$ electron capture detector (Voltage 47-60 $\mathrm{V}$ pulsed, pulse space $150 \mu \mathrm{S}$, pulse width $0.75 \pm 0.25 \mu \mathrm{S})$. The column packing was XE-60 on Gas chrom $Q$ support, at a loading of the stationary phase of about $0.3 \%$. This packing was prepared according to the method of Rapp and Eik-Nes. ${ }^{20} \mathrm{Col}-$ umns $(60 \mathrm{~cm}$ long and $0.4 \mathrm{~cm}$ internal diameter) were maintained at a temperature of $175^{\circ} \mathrm{C}$ and nitrogen was used as a carrier gas, at a flow rate of about 100 $\mathrm{ml} / \mathrm{minute}$. The temperature was selected on a trial and error basis to obtain maximal separation of a mixture of appropriate standard androgens. Steroids were chromatographed as the mono or diheptafluorobutyrates prepared as previously described. ${ }^{17-19}$

\section{TESTOSTERONE METABOLISM AND ABSORPTION,} IN VIVO

Rats were anaethestised with pentobarbitone (20-25 $\mathrm{mg} / \mathrm{kg}$ ), a tracheostomy performed, and a fine polyethylene catheter (external diameter $0.61 \mathrm{~mm}$ ) was passed 
retrogradely, into the portal vein via an ileocaecal vein. A second identical catheter in an internal jugular vein enabled replacement blood transfusion during portal vein sampling. $\left[1,2,6,7-{ }^{3} \mathrm{H}\right]$-testosterone $\left(15-20 \times 10^{6}\right.$ cpm, approximately $5.0 \times 10^{-8} \mathrm{M}$ ) in KRBG solution was introduced into a $30 \mathrm{~cm}$ closed loop of proximal jejunum which had been flushed with $0.9 \%$ sodium chloride (W/V) at $37^{\circ} \mathrm{C}$.

In a preliminary study, during which the portal vein was sampled intermittently for 40 minutes, peak tritium activity was present at approximately five minutes. In subsequent experiments the portal vein was sampled continuously for 10 minutes, and the blood collected as five separate $1.0 \mathrm{ml}$ samples, each covering a two minute period. Whole-blood was immediately extracted with 10 volumes diethyl ether. Aliquots of residual luminal fluid and gut tissue from the loop were also extracted, and the aqueous phase of all extracted samples was subjected to acid hydrolysis before reextraction with diethyl ether. Metabolites were separated by Celite column chromatography.

\section{Results}

17 $\beta$-HSD ACTIVITY IN DIFFERENT REGIONS OF GASTROINTESTINAL TRACT

Figure 1 shows $17 \beta$-HSD activity in different regions of rat gastrointestinal tract. Activity was significantly higher in gastric $(502 \pm 111 \mathrm{pmol} / \mathrm{mg} / \mathrm{min}$, mean \pm $\mathrm{SEM})$ and duodenal ( $595 \pm 166 \mathrm{pmol} / \mathrm{mg} / \mathrm{min})$ mucosa than that of either jejunum or ileum $(114 \pm 20$ and $29 \pm 2 \mathrm{pmol} / \mathrm{mg} / \mathrm{min}$ respectively; $P<0.05$ by

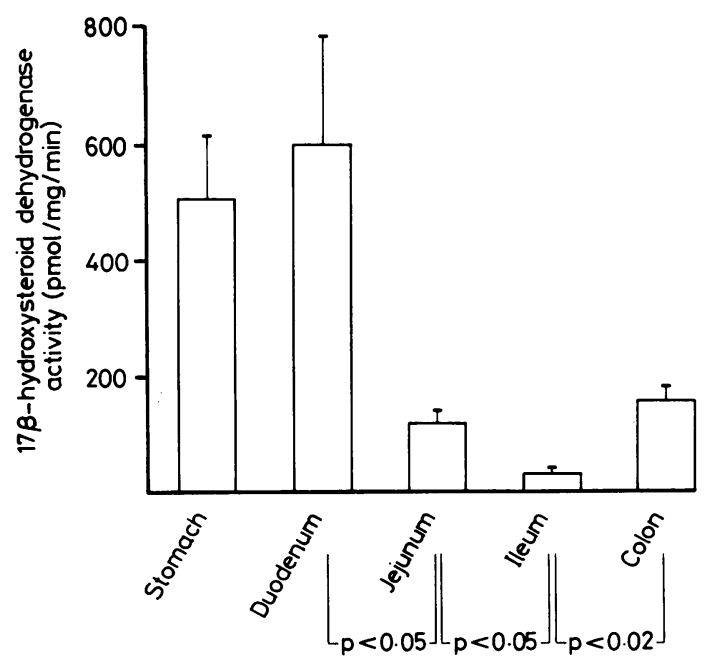

Fig. 1 17ß-hydroxysteroid dehydrogenase activity in mucosal homogenates of rat stomach, duodenum, jejunum, ileum and colon (mean $\pm S E M, n=4 ;$ Student's $t$ test).
Student's $t$ test). Activity in colonic mucosa (157 \pm 25 $\mathrm{pmol} / \mathrm{mg} / \mathrm{min}$ ) was significantly higher than that of ileum.

In one rat, $17 \beta$-HSD activity was estimated throughout the small intestine in mucosal homogenates derived from $15 \mathrm{~cm}$ segments of intestine. Figure 2 confirms that $17 \beta$-HSD activity is highest in the proximal small intestine and falls progressively until a small increase in activity in the distal ileum, which appears to anticipate the small but significant rise in colonic $17 \beta$-HSD activity (Fig. 1).

\section{TESTOSTERONE METABOLISM BY SLICES OF JEJUNUM}

Figure 3 shows Celite column chromatograms of testosterone metabolites in the incubation media of control and experimental incubations and also of metabolites in jejunal slices. In addition to testosterone and its major metabolite, androstenedione, two other peaks were present. One was a major metabolite in the tissue and eluted identically with dihydrotestosterone, and a second more polar metabolite, denoted X, eluted after testosterone.

\section{TESTOSTERONE METABOLISM AND TRANSPORT}

BY EVERTED SACS OF JEJUNUM

The same pattern of testosterone metabolites was found after incubation with everted rat jejunal sacs. Production of androstenedione, 'dihydrotestosterone', and $\mathrm{X}$ with respect to time, in mucosal and serosal media and in sac tissue is shown in Fig. 4.

Each point represents the mean of duplicate observations. Although androstenedione appeared as a

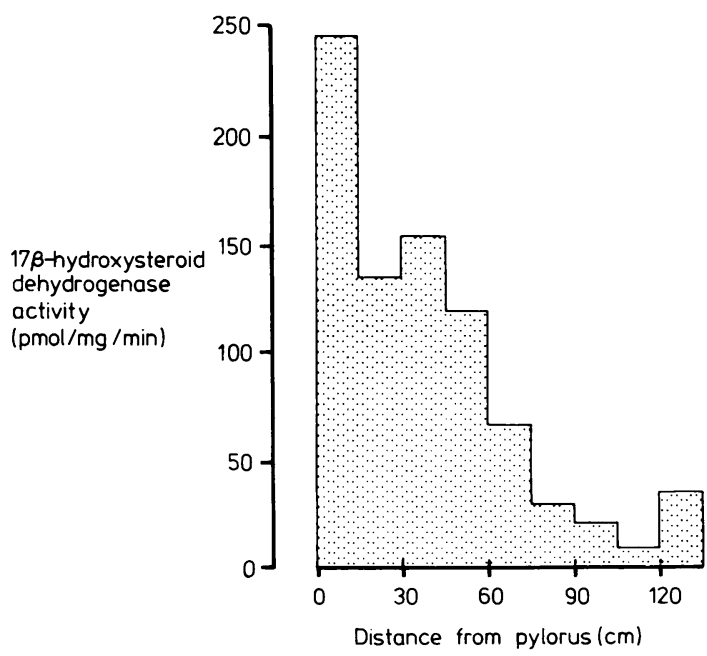

Fig. $217 \beta$-hydroxysteroid dehydrogenase activity in mucosal homogenates prepared from $15 \mathrm{~cm}$ segments along the small intestine of a male rat. 

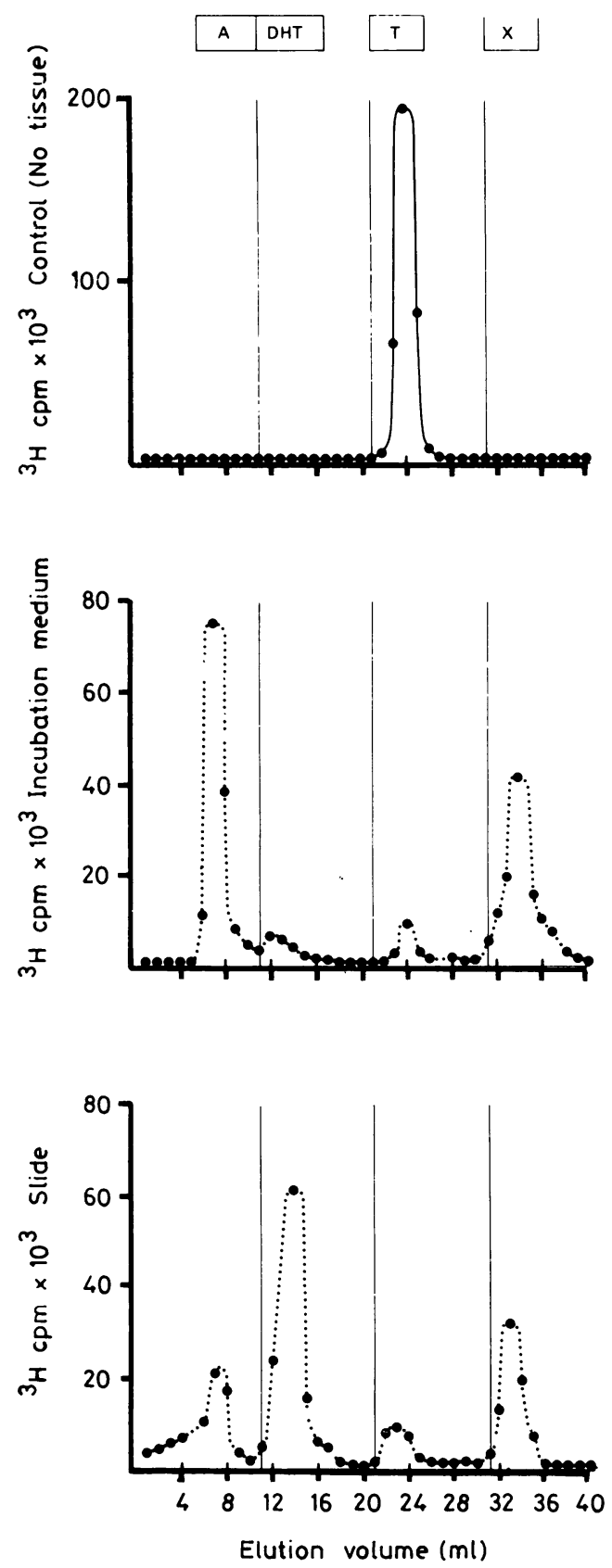

Fig. 3 Celite column chromatograms after incubation of testosterone with and without (control) slices of rat jejunum for 60 minutes. The lower two experimental chromatograms show $(\mathrm{H})$-metabolites in the incubation medium and in jejunal slices. Columns were eluted sequentially with isooctane $(10 \mathrm{ml}), 5 \%$ ethyl acetate $(10 \mathrm{ml}), 20 \%$ ethyl acetate $(10 \mathrm{ml})$ and $30 \%$ ethyl acetate $(10 \mathrm{ml})$ in iso-octane. The vertical lines indicate solvent changes. major early metabolite in the mucosal medium (Fig. $4 a)$, both 'dihydrotestosterone' and $X$ were major metabolites in sac tissue (Fig. 4c). Both entered the serosal medium more rapidly and were present at higher concentrations than either testosterone or androstenedione (Fig. 4c). Neither testosterone nor any of its metabolites was transported into the serosal medium against a concentration gradient. After 60 minutes incubation, $1.5 \%$ of the total tritium activity in the mucosal medium and $10.3 \%$ in the serosal medium was recovered after acid hydrolysis and re-extraction and more than half of this was found to be testosterone.

Recovery of tritium activity (including that liberated by acid hydrolysis) at each time point of the 60 minute incubation was between $89.6 \%$ and $92.6 \%$. All recoveries were therefore within the expected limits of this method, strongly suggesting that no other free or conjugated metabolites had been produced.

\section{FURTHER IDENTIFICATION OF TESTOSTERONE} METABOLITES BY GAS-LIQUID CHROMATOGRAPHY

Fractions corresponding to androstenedione, 'dihydrotestosterone', and $\mathrm{X}$ obtained by Celite column chromatography were subjected to gas-liquid chromatography. Peaks corresponding to monoheptafluorobutyrates of androstenedione and 'dihydrotestosterone' had retention times relative to testosterone diheptafluorobutyrate (retention time, 72 seconds) of 1.5 and 1.08 respectively, identical with their authentic standards. Peak X from the Celite column, however, resolved into four major peaks with relative retention times of $0.75,0.92,1.17$, and 1.42 . The first of these metabolites had the same retention time as authentic $5 \alpha$-androstane- $3 \alpha, 17 \beta$-diol diheptafluorobutyrate, but the identity of the others is uncertain and requires further clarification.

\section{TESTOSTERONE METABOLISM AND ABSORPTION, IN VIVO}

The pattern of portal vein metabolites shown in Fig. 5 is a representative example of the three experiments performed. In the first sampling period (0-two minutes) the major metabolite was androstenedione and this accounted for $63.5 \%$ of the total tritiated metabolites in the portal blood at this time (Table 1). In contrast, only minor amounts of unaltered testosterone entered the portal circulation. Although other, as yet, unidentified metabolites (e, f, and g, Fig. 5) entered the portal vein during later sampling periods, androstenedione continued to predominate. A metabolite eluting identically with dihydrotestosterone was also present in the four to six minute sample but again this made a relatively minor contribution to the total tritium activity. A similar pattern of metabolites was found in the residual fluid in the gut lumen and in the gut tissue of the loop of jejunum (Fig. 6). 
(a)

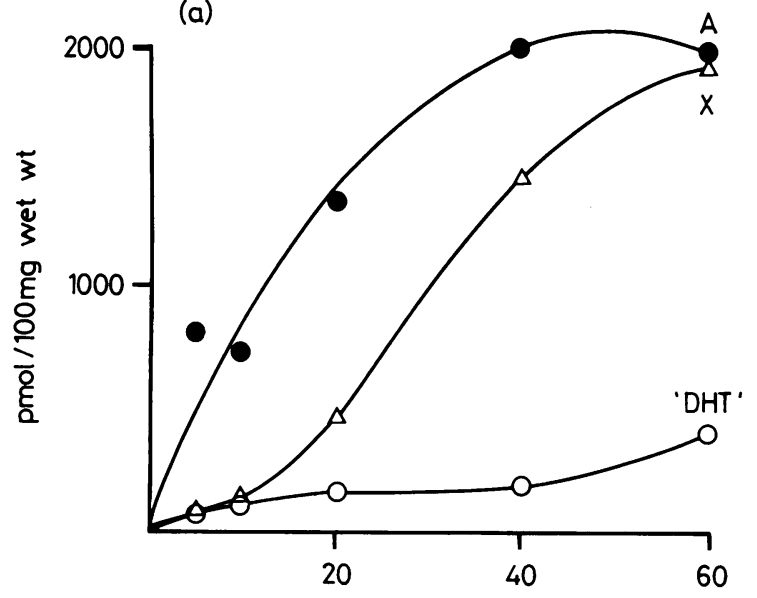

(b)

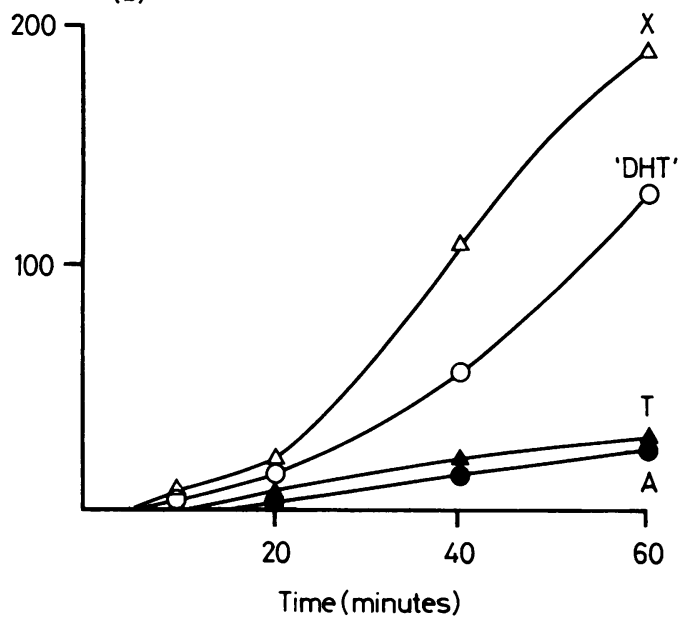

(c)

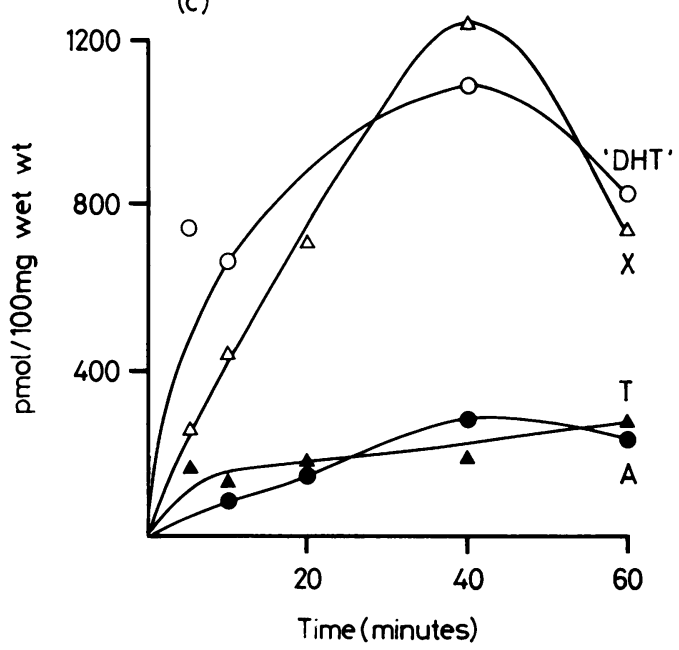

Fig. 4 Testosterone metabolites in the (a) mucosal medium, (b) serosal medium and (c) iissue of everted sacs of rat jejunum, with respect to time of incubation. Each point represents the mean of duplicate observations. $T$, testosterone; $A$, androstenedione, 'DHT', dihydrotestosterone; $X$, unidentified metabolite.

Table $1 \quad\left[{ }^{3} \mathrm{H}\right]$-Testosterone metabolites in portal blood, gut lumen and gut tissue after introduction of $\left[{ }^{3} \mathrm{H}\right]$-testosterone into a closed loop of proximal rat jejunum

\begin{tabular}{|c|c|c|c|c|c|c|c|c|c|}
\hline \multirow{3}{*}{$\begin{array}{l}\text { Sampling } \\
\text { period } \\
\text { (min) }\end{array}$} & \multicolumn{3}{|c|}{ Portal blood } & \multicolumn{6}{|c|}{ Jejunum } \\
\hline & \multicolumn{3}{|c|}{$\%$ Total metabolites } & \multicolumn{3}{|c|}{$\begin{array}{l}\text { Luminal fluid } \\
\% \text { Total metabolites }\end{array}$} & \multicolumn{3}{|c|}{$\begin{array}{l}\text { Tissue } \\
\% \text { Total metabolites }\end{array}$} \\
\hline & $\% T$ & $\% A$ & \% Others & $\% T$ & $\% A$ & $\%$ Others & $\% T$ & $\% A$ & \% Others \\
\hline $\begin{array}{l}0-2 \\
2-4 \\
4-6 \\
6-8 \\
8-10\end{array}$ & $\begin{array}{l}4 \cdot 4 \\
4 \cdot 1 \\
3 \cdot 3 \\
3 \cdot 5 \\
5 \cdot 5\end{array}$ & $\begin{array}{l}63 \cdot 5 \\
46 \cdot 2 \\
42 \cdot 7 \\
48 \cdot 3 \\
47 \cdot 7\end{array}$ & $\begin{array}{l}32 \cdot 1 \\
49.7 \\
54.0 \\
48.2 \\
48.4\end{array}$ & $\begin{array}{l}\bar{z} \\
\overline{17} \cdot 5\end{array}$ & $\begin{array}{l}- \\
\overline{43 \cdot 4}\end{array}$ & $\begin{array}{l}- \\
\overline{3} \\
39 \cdot 1\end{array}$ & $\begin{array}{l}- \\
\overline{14 \cdot 7}\end{array}$ & $\begin{array}{l}- \\
\overline{57 \cdot 1}\end{array}$ & $\begin{array}{l}- \\
\overline{-} \\
28 \cdot 2\end{array}$ \\
\hline
\end{tabular}

$\mathrm{T}$, testosterone; $\mathrm{A}$, androstenedione. 
Recovery of tritium activity before and after acid hydrolysis from portal blood, luminal fluid and gut tissue is shown in Table 2. The proportion of the total tritium activity liberated by acid hydrolysis was only $0.03 \%$ in portal blood, suggesting that the majority of tritium activity entering the circulation was free steroid. Although overall tritium recovery was low (38.5\%), this can be accounted for by the fact that only $5 \%$ of the estimated portal blood flow was sampled that is, $0.5 \mathrm{ml} / \mathrm{min}$ of approximately $10 \mathrm{ml} / \mathrm{min}^{21}$ Applying this correction to the tritium recovery in portal blood, total recovery rises to $86 \%$, which is within the expected range for our method of extraction and chromatography.

Table 2 Recovery of tritiated metabolites from portal blood, luminal fluid, and jejunal tissue

\begin{tabular}{|c|c|c|c|c|}
\hline \multirow[t]{3}{*}{ Metabolites } & \multicolumn{4}{|c|}{$\%$ Of total tritium activity } \\
\hline & \multirow[t]{2}{*}{ Portal blood } & \multicolumn{3}{|l|}{ Jejunum } \\
\hline & & $\begin{array}{l}\text { Luminal } \\
\text { fluid }\end{array}$ & Tissue & Total \\
\hline \multirow{2}{*}{$\begin{array}{l}\text { Ether- } \\
\text { extractable } \\
\text { Liberated by } \\
\text { hydrolysis } \\
\text { Total }\end{array}$} & $2 \cdot 5$ & $6 \cdot 5$ & $23 \cdot 9$ & 32.9 \\
\hline & $\begin{array}{l}0.03 \\
2.53\end{array}$ & $\begin{array}{l}1 \cdot 3 \\
7.8\end{array}$ & $\begin{array}{r}4 \cdot 3 \\
28 \cdot 2\end{array}$ & $\begin{array}{c}5 \cdot 6 \\
38 \cdot 53\end{array}$ \\
\hline
\end{tabular}

\section{Discussion}

17 $\beta$-HYDROXYSTEROID DEHYDROGENASE ACTIVITY We have previously suggested that small intestinal $17 \beta$-HSD may have a physiological role in the peripheral oxidative metabolism of testosterone in man and animals. ${ }^{1}$ The present study confirms these earlier findings and in addition demonstrates high specific activities of $17 \beta$-HSD in gastric and duodenal mucosa and moderate activity in colonic mucosa. The previous assessment of the overall capacity of the small intestine to oxidise testosterone to the weaker androgen androstenedione $e^{1}$ is clearly an underestimate of the total capacity of the gastrointestinal tract. 17 $\beta$-HSD activity decreased with distal progression along the small intestine, an observation which is paralleled by the fall in UDP-glucuronyl transferase activity, ${ }^{22}$ the enzyme required for glucuronide synthesis. Conjugation of steroids and other substances prevents absorption and hastens excretion in the faeces, the clinical importance of which has been clearly shown for oestrogens. ${ }^{23} \mathrm{~A}$ similar detoxifying or degrading role may also exist for intestinal $17 \beta$-HSD, as it is capable of reducing the potency of testosterone and possibly oestradiol.
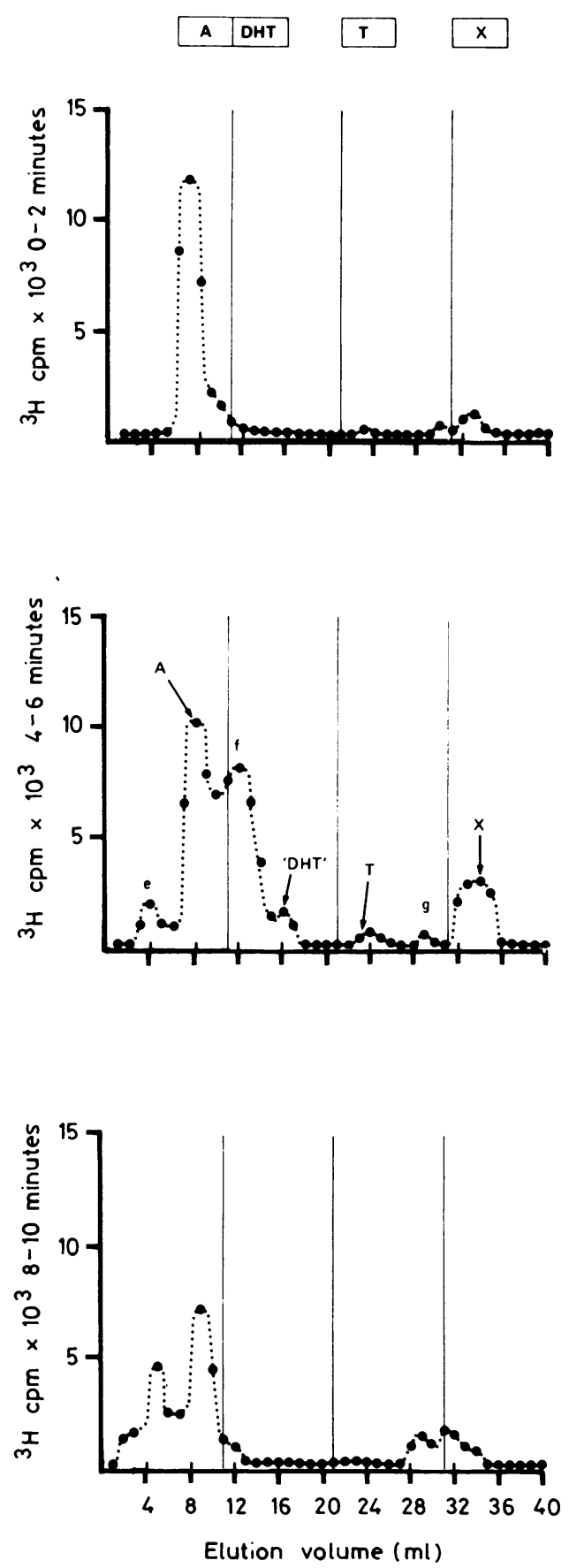

Fig. 5 Celite column chromatograms showing portal vein $\left.{ }^{3} \mathrm{H}\right]$-metabolites during three, 2-minute sampling periods after introduction of $\left[{ }^{3} \mathrm{H}\right]$-testosterone into a closed jejunal loop in rat, in vivo. $T$, testosterone; $A$, androstenedione; 'DHT', dihydrotestosterone; $X$, e f and $g$, unidentified metabolites. 

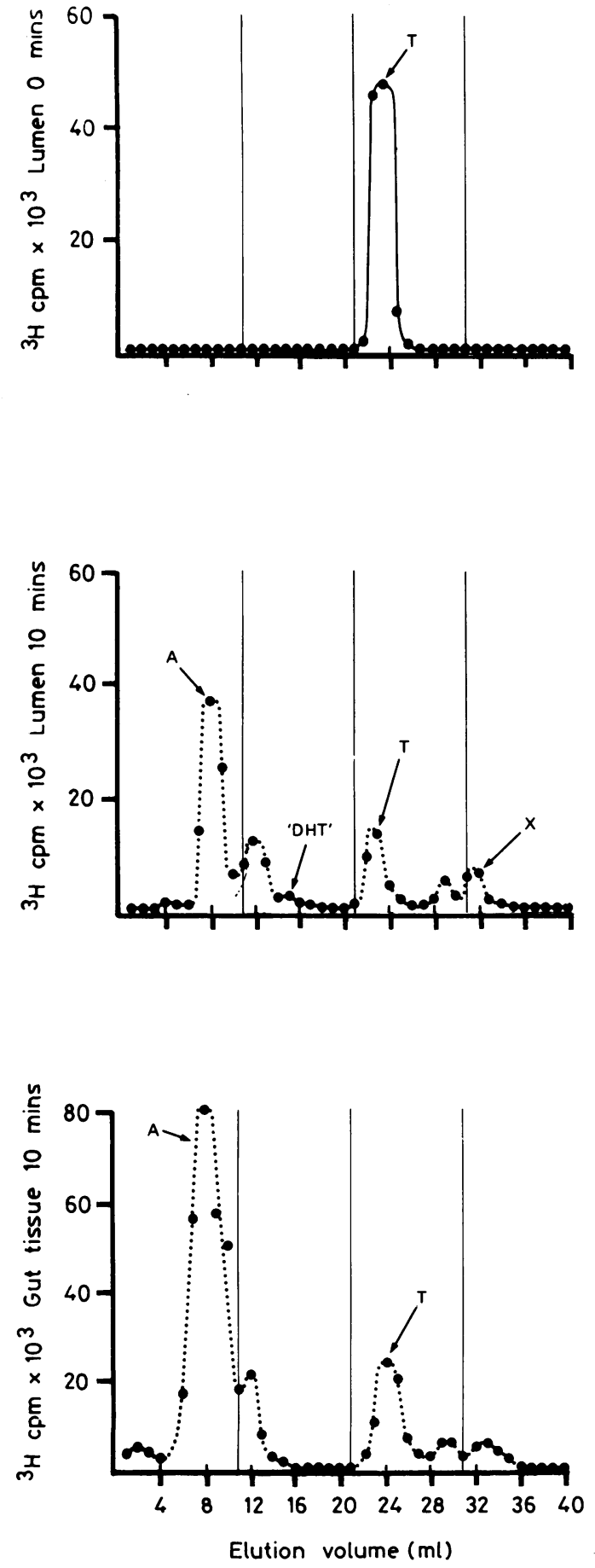

Fig. 6 Celite column chromatograms of $[3 \mathrm{H}]$-metabolites of testosterone in the lumen and gut tissue of a closed loop of rat jejunum. $T$, testosterone; $A$, androstenedione; 'DHT', dihydrotestosterone; $X$, unidentified metabolite.
$5 \alpha$-REDUCTASE ACTIVITY

Observations on testosterone metabolism by slices and everted sacs of rat jejunum agreed with previous reports $^{7-11}$ which suggested that a variety of metabolites, including probably dihydrotestosterone are also produced by mammalian intestine. Experiments with everted gut sacs indicated that 'dihydrotestosterone' and the more polar metabolites, collectively designated as $\mathrm{X}$, entered the serosal medium more rapidly than either testosterone or androstenedione, suggesting that these additional metabolites may be important contributors to circulating levels of plasma androgens. These findings conflict with those of Kreek et al. ${ }^{7}$ who found that $5 \alpha$-androstane- $3 \alpha, 17 \beta$-diol glucuronide accumulated against a concentration gradient and was the major metabolite in the serosal medium of everted gut sacs. Contrary to the views of Schedl ${ }^{24} 25$ it was proposed that glucuronidation was an important factor in the intestinal absorption of androgens, but, based on the results of acid hydrolysis, the present study has failed to confirm this. It should be noted that Kreek et al. ${ }^{7}$ used a much longer incubation period of two to three hours and the conjugate in the serosal medium was produced mainly in the last two hours of the incubation. This is a period when there is gross structural disorganisation of gut sac mucosa. ${ }^{26}$

TESTOSTERONE METABOLISM, IN VIVO

Intestinal testosterone metabolism in the rat in vivo was qualitatively different from the findings in everted sacs, for, like the present and previous observations with mucosal homogenates, ${ }^{1}$ the oxidised product androstenedione was the major metabolite in portal blood, gut tissue, and luminal fluid. Other metabolites were produced in vivo, but we found no evidence that these were absorbed preferentially, as was the case in experiments with everted gut sacs. The most likely explanation for this disparity between the findings in vitro and those in vivo is that reduction of testosterone was favoured in the in vitro tissue by a lower oxidation-reduction potential produced in relatively hypoxic tissue. The early appearance of metabolite 'dihydrotestosterone' in the serosal medium of everted gut sacs suggests that reduction was facilitated throughout the incubation and was not merely a feature of a deteriorating preparation during the final stages of the experiment. The relatively high concentration of 'dihydrotestosterone' found in the tissue would support this hypothesis.

It has been shown in erythrocytes ${ }^{27}$ and liver ${ }^{28}$ that oxidation of testosterone is favoured when the $\mathrm{pH}$ is above 7.4. Accumulation of the products of anaerobic metabolism such as lactic acid ${ }^{14}$ will inhibit this conversion. It is accepted that intestinal absorption of some substances - particularly drugs - is reduced in vitro, ${ }^{29}$ but qualitative changes in metabolic pathways can clearly produce highly misleading results. This empha- 
sises the need for caution in the interpretation of such in vitro studies.

\section{CLINICAL IMPLICATIONS}

A reversible abnormality of plasma androgens has been described in men with untreated coeliac disease. ${ }^{30}$ It was suggested that impaired $5 \alpha$-reduction of testosterone in the gut might account for this abnormality, particularly as at least $70 \%$ of plasma DHT is derived from peripheral conversion of testosterone. ${ }^{31}$ The present study failed to identify dihydrotestosterone as a major portal vein metabolite, which makes it highly unlikely that the intestine is an important source of circulating dihydrotestosterone. This contention is supported by a recent study in man. ${ }^{32}$

The present study provides further evidence that intestinal mucosal $17 \beta$-HSD activity, rather than metabolism by the liver, ${ }^{33}$ is the major factor leading to the testosterone's lack of oral potency. ${ }^{34}$ Protection of the 17-position by addition of a methyl group to testosterone produces an orally active androgen ${ }^{33}$ which is clearly no longer a substrate for $17 \beta$-HSD. This emphasises the importance of the enzyme 17 $\beta$-HSD in determining the fate of orally ingested androgens and possibly oestrogens.

Intestinal $5 \alpha$-reductase activity may contribute to the potency of a new orally active testosterone ester, testosterone undecanoate (TU ${ }^{35-37}$ by its conversion to $5 \alpha$-DHTU in the intestine. Plasma dihydrotestosterone levels were restored before testosterone levels in hypogonadal men receiving replacement therapy with testosterone undecanoate. In addition, $5 \alpha$-reduction of testosterone to dihydrotestosterone may be necessary before testosterone can exert its stimulatory effects on intestinal epithelial cell proliferation ${ }^{38}{ }^{39}$ and on the activity of certain mucosal glycolytic enzymes. ${ }^{40}$

The present study confirms that the gastrointestinal tract has the potential to take an active role in peripheral androgen metabolism and may directly influence the plasma concentrations of some circulating androgens. In addition, the gut is likely to be an important factor determining the oral potency of androgens and possibly other steroids, as evidence is accumulating that the gut is also involved in the metabolism of oestrogens, ${ }^{41}$ progesterone, ${ }^{42}{ }^{43}$ hydrocortisone, ${ }^{44}$ and aldosterone. ${ }^{45}$

MJGF gratefully acknowledges the support of the Wellcome Trust. The authors also wish to thank Dr P D Fairclough for his assistance in developing the portal vein sampling technique.

\section{References}

1 Farthing MJG, Vinson GP, Edwards CRW, Dawson AM. $17 \beta$-hydroxysteroid dehydrogenase activity in the mucosa of rat and human small intestine. J Steroid Biochem 1981; 14:1107-13.

2 Krieg M, Szalay R, Voigt KD. Binding and metabolism of testosterone and of $5 \alpha$-dihydrotestosterone in bulbocavernosus/ levator ani (BCLA) of male rats: in vivo and in vitro studies. J Steroid Biochem 1974; 5:453-9.

3 Massa R, Martini L. Testosterone metabolism: A necessary step for activity? J Steroid Biochem 1974; 5:941-7.

4 Milewich L, Parker PS, MacDonald PC. Testosterone metabolism by human lung. J Steroid Biochem 1978; 9:29-32.

5 Bleau G, Roberts KD, Chapdelaine $A$. The in vitro and in vivo uptake and metabolism of steriods in human adipose tissue. J Clin Endocrinol Metab 1974; 39:236-46.

6 Blohm TR, Laughlin ME. Androgen metabolism in adipose tissue: conversion of $5 \alpha$-Dihydrotestosterone to $3 \alpha$ androstanediol by hamster tissue. J Steroid Biochem 1978; 9:603-8.

7 Kreek MJ, Guggenheim FG, Ross JE, Tapley DF. Glucuronide formation in the transport of testosterone and androstenedione by rat intestine. Biochim Biophys Acta 1963; 74:418-27.

8 Harri MP, Hartiala K, Nienstedt W, Salmi HA. Testosterone metabolism by gastrointestinal microsomes. Acta Physiol Scand 1970; 79:537-40.

9 Harri MP, Neinstedt W, Hartiala K. Testosterone metabolism by canine intestine. Suomen Kemistilehti B 1970; 11:395-401.

10 Naftolin F, Mulay S, Solomon S. Studies on the metabolism of dihydrotestosterone by gut and gut content in the male rat. In: Troen P, Nankin HR. The testis in normal and infertile men. New York: Raven Press.

11 Nienstedt W, Ahotupa M, Hietanen E. Metabolism of testosterone and androstenedione by human adult and fetal gastrointestinal tissues in vitro. J Steroid Biochem 1980; 13:1421-5.

12 Lowry OH, Rosebrough NJ, Farr AL, Randall RJ. Protein measurement with the folin phenol reagent. $J$ Biol Chem 1951; 193:265-75.

13 Crane RK, Mandelstam P. The active transport of sugars by various preparations of hamster intestine. Biochim Biophys Acta 1960; 45:460-76.

14 Wilson TH, Wiseman G. The use of sacs of everted small intestine for the study of the transference of substances from the mucosal to the serosal surface. J Physiol 1954; 123:116-25.

15 Dahlqvist A. Determination of maltase and iso maltase activities with a glucose oxidase reagent. Biochem J 1961; 80:547-51.

16 Lloyd JB, Whelan WJ. An improved method for enzymic determination of glucose in the presence of maltose. Analyt Biochem 1969; 30:467-70.

17 Vinson GP, Goddard C, Whitehouse BJ. Corticosteroid production in vitro by adrenal tissue from rats with inherited hypothalamic diabetes insipidus (Brattleboro strain). J Steroid Biochem 1978; 9:657-65.

18 Vinson GP, Bell JBG, Whitehouse BJ. Production of testosterone and corticosteroids by the rat adrenal gland in vitro and the effects of stimulation with ACTH, LH and FSH. J Steroid Biochem 1976; 7:407-11.

19 Vinson GP, Whitehouse BJ, Goddard C. Steroid hydroxylation and androgen production by incubated rat adrenal tissue. J Steroid Biochem 1978; 9:677-83. 
20 Rapp JP, Eik-Nes KB. Determination of deoxycorticosterone and aldosterone in biological samples by gas chromatography with electron capture detection. Analyt Biochem 1966, 15:86-408.

21 Altman PL, Dittmer DS, eds. Biology data book, vol. 3, Bethesda, Maryland; Federation of American Societies for Experimental Biology. 1974: 1705.

22 Hanninen O, Aitio A, Hartiala K. Gastrointestinal distribution of glucuronide synthesis and the relevant enzymes in the rat. Scand J Gastroenterol. 1968; 3:461-4.

23 Tikkanen MJ, Pulkkinen MO, Aldercreutz H. Effect of ampicillin treatment of urinary excretion of estriol conjugates in pregnancy. J Steroid Biochem 1973; 4:439-40.

24 Schedl HP. Absorption of steroid hormones from the human small intestine. J Clin Endocrinol Metab 1965; 25:1309-16.

25 Schedl HP, Clifton JA. Small intestinal absorption of steroids. Gastroenterology 1961; 41:491-9.

26 Levine RR, McNary WK, Kornguth PJ;Le Blanc R. Histological re-evaluation of everted gut sac technique for studying intestinal absorption. Eur J Pharmacol 1970; 9:211-9.

27 Mulder E, Lamers-Stahlhofen GJM, Van der Molen HJ. Isolation and characterisation of 17-hydroxysteroid dehydrogenase from human erythrocytes. Biochem J 1972; 127:649-59.

28 Littman KP, Gerdes H, Winter G. Kinetik und charakterisieurung der ostradiolsensitiven 17-beta-hydroxysteroiddehydrogenasen in der menschlichen leber. Acta Endocrinol (Copenh) 1971; 67:473-82.

29 Ochsenfahrt $\mathrm{H}$. The mucosal-serosal transfer of drugs in the rat jejunum with and without blood flow. NaunynSchmiedebergs Arch Pharmacol 1971; R102.

30 Green JRB, Goble HL, Edwards CRW, Dawson AM. Reversible insensitivity to androgens in men with untreated gluten enteropathy. Lancet 1977; 1:280-2.

31 Ito T, Horton R. The source of plasma dihydrotestosterone in man. J Clin Invest 1971; 50:1621-7.

32 Ishimaru T, Edmiston A, Pages L, Horton R. Direct conversion of testosterone to dihydrotestosterone glucuronide in man. J Clin Endocr Metab 1978; 47:1282-6.
33 Foss GL, Simpson SL. Oral methyltestosterone and jaundice. $\mathrm{Br}$ Med J 1959; 1:259-63.

34 Foss GL. Clinical administration of androgens. Lancet $1939 ; 236: 502-4$.

35 Coert A, Geelen J, de Visser J, van der Vies J. The pharmacology and metabolism of testosterone undecanoate (TU), a new orally active androgen. Acta Endocrinol (Copenh) 1975; 79:789-800.

36 Nieschlag E, Mauss J, Coert A, Kicovic P. Plasma androgen levels in men after oral administration of testosterone or testosterone undecanoate. Acta Endocrinol (Copenh) 1975; 79:366-74.

37 Franchimont P, Kicovic PM, Mattei A, Roulier R. Effects of oral testosterone undecanoate in hypogonadal male patients. Clin Endocrinol 1978; 9:313-20.

38 Wright NA, Morley AR. The effect of testosterone on the growth fraction of the mouse small intestine. $J$ Endocrinol 1971; 50:351-2.

39 Wright NA, Morley AR, Appleton D. The action of testosterone on cell proliferation and differentiation in the small bowel. J Endocrinol 1972; 52:161-75.

40 Lufkin EG, Stifel FB, Herman RH, Rosensweig NS. Effect of testosterone on jejunal pyruvate kinase activities in normal and hypogonadal males. J Clin Endocrinol 1972; 34:586-91.

41 Smith FR, Tapley DF, Ross JE. Glucuronide formation in the transport of estradiol by rat intestine in vitro. Biochim Biophys Acta 1963; 69:68-73.

42 Nienstedt W, Hartiala K. Steroid metabolism by the canine intestine. I. Qualitative experiments with progesterone. Scand J Gastroenterol 1969; 4:483-8.

43 Harri MP, Nienstedt W, Hartiala K. Steroid metabolism by the canine intestine. II. The metabolism of progesterone by the jejunal mucosa in vitro. Scand J Gastroenterol 1970; 5:415-9.

44 McCormick JR, Herman AH, Lien WM, Egdahl RH. Hydrocortisone metabolism in the adrenalectomized dog: the quantitative significance of each organ system in the total metabolic clearance of hydrocortisone. Endocrinology 1974; 94:17-26.

45 Balikian HM. Metabolism of aldosterone by the splanchnic organs of the dog. Endocrinology 1971; 89:1309-13. 